\title{
Esophageal resection in the ederly
}

\author{
G Sammarco*, G Vescio, A Puzziello, E Marra, R Sacco \\ From de Senectute: Age and Health Forum \\ Catanzaro, Italy. 5-7 December 2009
}

\section{Background}

The aging of the population and longer life expectancy entails an increased number of elderly patients with esophageal cancer and benign pathologies referred for surgical treatment. Esophageal cancer is a pathology that mainly involves elderly patients. The aim of this study is to assess the effects of age on the outcome of surgery for esophageal cancer and benign pathologies in patients treated in our department.

\section{Materials and methods}

61 patients with esophageal pathology have been treated from 2001 to2009(23 benign;38 malignant). Patients have been accurately examined in the pre-operatory stage. According to our protocol patients underwent: oral cavity and septic cariogenic focuses drainage- correction of malnutrition and hydro-electrolytic imbalance- correction of possible immunodepression- respiratory preparation- antibiotic therapy of silent bronchopulmonary infections - deep venous thrombosis prophilaxis- concomitant pathologies treatment. We perform: total esophagectomy in cervical and thoracic carcinoma- subtotal esophagectomy with intrathoracic anastomosis in lower third carcinoma of the esophagus. Ways of access: laparotomy with right thoracotomy and presterno-cleidomastoid cervicotomy for total esophagectomies or left thoraco-phrenolaparotomy for subtotal esophagectomies with endothoracic anastomosis. Heller-Belsey myotomia in achalasia of the cardia- Belsey Mark IV antireflux procedure in hiatus hernia.

\section{Results}

Global Mortality: 5\% ( this result is significantly correlated with the major complexity of the treatment which includes esophagectomy and consequent reconstruction). No cases of mortality related to non-resective

Table 1 perioperative morbidity and mortality in order to surgical treatments

\begin{tabular}{llll}
\hline Operation & N & Morbidity & Mortality \\
\hline Esophagectomy(cervical anastomosis) & 28 & $2(7 \%)$ & $2(/ \%)$ \\
Esophagectomy & 12 & $2(16 \%)$ & $1(8 \%)$ \\
(thoracic anastomosis) & & & \\
Heller & 11 & $1(9 \%)$ & - \\
Mark IV & 8 & - & - \\
Myotonia-divertculopessi & 2 & - & - \\
TOTAL & 61 & $5(8 \%)$ & $3(5 \%)$ \\
\hline
\end{tabular}

procedures such as myotomia and fundoplication have been registered (Morbidity: 8\%), Table 1.

\section{Conclusions}

Anastomotic leak and fistulization represent, in our experience and in those cases reported in the literature, the main complications in resective operations. Both morbidity and mortality reflect what has been reported in other case series; this led to consideration of the acceptability of the risk related to the esophageal surgery and the possibility to perform the thoracic access, in patients over 70 years of age, provided that some conditions such as the detection of preexisting and concomitant pathologies and an accurate preoperative preparation of the patient are met. Advanced age should not be relied on as a contraindication to esophageal resection especially if surgery represents the only possible way of treatment, as in the case of malignancy, but surgeon's efforts must be directed towards a meticulous pre-operative diagnosis and prophylaxis of comorbidities.

\section{Published: 19 May 2010}

\section{References}

1. Cui $\mathrm{Y}$, Chen $\mathrm{H}$ : Esophagectomy in elderly over 70 years of age. Ann. Thorac.Surg. 2002, 74(4):1291-1292. 
2. Ruol A, Portale G, Zaninotto G, et al: Results of esophagectomyfor esophageal cancer in elderly patients: age has little influence on loutcomeand survival. J Thorac Cardiovasc Surg. 2007, 133(5):1186-92.

doi:10.1186/1471-2318-10-S1-A34

Cite this article as: Sammarco et al:: Esophageal resection in the ederly. BMC Geriatrics 2010 10(Suppl 1):A34.

Submit your next manuscript to BioMed Central and take full advantage of:

- Convenient online submission

- Thorough peer review

- No space constraints or color figure charges

- Immediate publication on acceptance

- Inclusion in PubMed, CAS, Scopus and Google Scholar

- Research which is freely available for redistribution

Submit your manuscript at www.biomedcentral.com/submit
Ciomed Central 